\title{
SUSTAINABLITY \& ENVIROMENTAL APPROACH TO CONSTRUCTION INDUSTRY: USING RCA IN TO SCC
}

\author{
Srinivas Vasam ${ }^{1}$, K. Jagannadha Rao ${ }^{2}$, M.V.Seshagiri Rao ${ }^{3}$ \\ ${ }^{1}$ Research Scholar, Department of Civil Engineering - JNTUH-Hyderabad, India \\ ${ }^{2}$ Professor, Department of Civil Engineering, Chitanya Bharathi Institute of Technology, Hyderabad, India \\ ${ }^{3}$ Professor, Department of Civil Engineering, JNTUH CE Hyderabad, India
}

\begin{abstract}
Indian construction industry the Sustainability development is for setting up a vision for the economy to achieve the major challenges such as social and economic development, environmental protection. Sustainability is the main criteria of any construction and making use of sustainable material so as to moving towards the reduction of emission of carbon footprints in the construction industry.

In this paper the concepts of sustainability environmental protection using Eco-friendly materials which have been an revolution in the construction industry and also discuss in detail about the Environmental Management System which needed to be implemented in any project of construction industry. The Recycled Concrete Aggregate (RCA) is used as aggregate for production of new concrete i.e Self Compacting Concrete (SCC) with RCA was investigated. The performance of strengths produced by using Recycled Concrete Aggregate (RCA) in to concrete and results are compared with using the Natural Aggregate Concrete (NAC). The extraction of materials and Reuse of recycled Concrete aggregates from old constructions and Demolished Concrete Waste in production of new concrete as innovation of Indian concrete industry and the need for more civil and industrial infrastructures and development $s$, have unfortunately led to the unacceptable shortage and depletion of raw materials, increasing amounts of old Construction and demolition waste $(C \& D W)$ and accelerated deterioration of the natural environment at worldwide
\end{abstract}

Keywords: Sustainability, Environmental Management Plan, Sustainable materials, Construction industryRecycled concrete aggregate, Self Compactiing concrete.

\section{INTRODUCTION}

Many countries having understood the importance of sustainability, the sustainability has now become paradigm in the field of engineering and has been a burning topic in which many are doing researches which might carry out even for few more future decades. Sustainability development is for setting up a vision for the economy to achieve the major challenges such as social and economic development, environmental protection

The word "sustainability" is the most predominant word that is being in use across the globe since past decade. Not a professional is unaware of this word may be hypothetical but indeed it is the sublime truth. from many researchers observation he has been identified the sustainability in three important aspects such as sustainability in terms of Environmental, Social and Economic.

* Environmental Sustainability: It is the one which is achieved by making practices in such a way so as to make use the natural resources in prioritise basis and at the same time to reduce the pollution by controlling the emissions of $\mathrm{CO}_{2}$ gases and constructional or any other wastes generated that causes pollution.
* Social Sustainability: The Social Sustainability is the one which is achieved by identifying the needs of all those were interconnected with the project, the whole supply chain. The local communities and the end used should also be handled.

* Economic Sustainability: Economic Sustainability is the one which deals with effective implementation of practicing the proper usage of available resources such as nature, human and energy.

Green building is the word that comes when we think about sustainable design. Green building means constructing the building in safe surrounding environment which will not create negative impact on the natural environment and constructing the building by using the materials of friendly environment and locally available. The main concept of this type of buildings is to reduce the pollution as much as possible

Approach towards sustainability in many ways shall benefit the construction industry and also the environment around it by simple application of sustainable concepts which can be adhered not only by large construction industries but also by every individual, some of them are as follows: 
Use of Solar Power System: This is the most common approach by which the power utilization can be done in environmental friendly manner; this sort of approach has been successfully implemented across the globe globally. The installation is also very easy and all it needed is to install solar panels on the roofs top of buildings and thereby generate your own electricity. Even now the government bodies have taken an initiative on mass production of electricity by solar power technology to tmeet the current electricity crisis.

Rain Water Harvesting: From the recent studies, there has been a projection of water deficient in the coming decades as underground water has been gradually decreasing due to major junk of pollution. As a humane part the possible sustainable construction application in to conserve the water for effective utilization of human needs. So by proper managing of the rain water we can reduce the use of natural resource.

Green Roofs and Walls: The use and implementation of Green Roofs, Green walls and complementary features , elements can contribute significantly to meeting the challenge of sustainable development and it give more features .

Retrofit of Existing Buildings: Renovating the existing building would be a tedious task. The main aim of energy efficiency is to reduce the energy consumption considerably by $30-40 \%$. Some of the energy efficient aspects that needs to considered during retrofitting are:

* Retrofit complete building with energy efficiency light bulbs, room sensors, etc.

* Adoption of solar panel technology

* Removal of extremely hazardous asbestos by applying insulation.

* Providing efficient window seals to prevent cold air/hot air leaving from building.

* Make sure that these retrofit buildings get a silver rating from LEED Green Building Council (GBC).

Green Buildings Materials: In the move for establishing the sustainable development, the adoption of environmental management of the construction materials is an essential move that is needed to be pursued to demonstrate the sustainable practices of recycling, reusing and reducing of construction materials wastage. The sustainable materials are the one those keep the building sustainable for all types of weather and by constructing such buildings we can reduce the carbon monoxide footprint of the building on environment and even it provides the direct cost savings to the building owners.

Nano Materials: Nano- Materials are the one, the materials with size less than 100 nanometers. In general terms it can be defined as the materials which are 10,000 times smaller than the diameter of human hair are termed as Nanomaterials. The advent of nanotechnology has made the existence of these nano materials; these have changed the entire ideology of materials sizes, its properties.

\section{SUSTAINABLE USAGE OF EXISTING CONSTRUCTION MATERIALS}

Some of the essential construction materials that are vulnerable to wastage and the ways which they can be employed in an environmental oriented manner are discussed in details. The major problem lies is with construction and demolition wastages. In these attempts resulting in the wastage of construction materials, there is an on-going increased loss of several potential materials that can be reutilised by placing all the necessary requirements in place for the recycling facilities to deliver effective deliverables after the recycling process.

Environmental Management System : Environmental performance of a construction organization should always be improved by optimizing some adequate set of environmental practices. According to Shen and Tam (2002), the ISO 14001 Standard is designed in such a manner that it demonstrates continual improvement by establishing the incorporation of the following dimensions in to the organizational activities,

- Environmental Policy

- Planning

- Implementation and operation

- Checking and correcting actions

- Measurement review and improvement

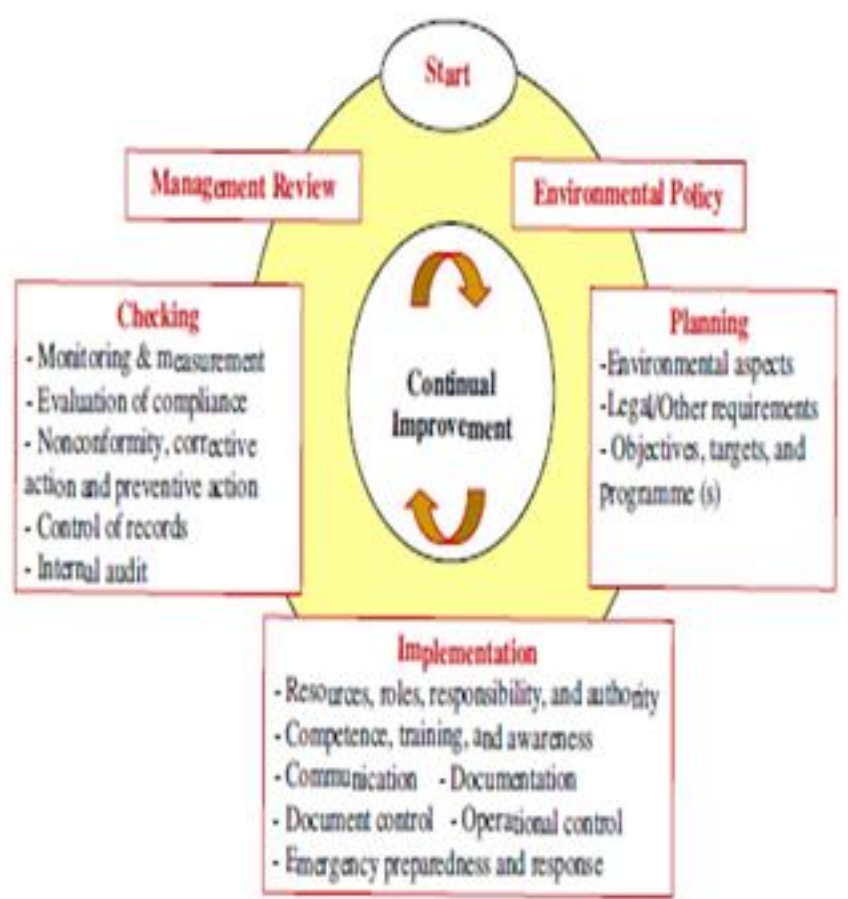

Fig4. Above figure presents the processes required in an ISO 14001 Certified organisation to accomplish continual improvement Sakr et al. (2010, p.214). 


\section{SUSTAINABILITY IN CONCRETE}

\section{PRODUCTION}

The present use of natural resources in consideration of Environment, Ecological and Economical aspects forms the basis for sustainable developments and Approaches . for Construction materials and methods to be Low energy consumption and less pollution during production and the using of maximum by-products as well as waste materials and recycled materials are essential to reduce environmental , social and financial impacts.

This paper gives an overall method and design approach for the design of sustainable concrete mixes and covers therefore a broad field of relevant subjects in concrete technology. The different subjects show a close relation in terms of sustainability and multifunctional use of raw materials. In this respect, the knowledge from different fields is required nowadays for the design of sustainable concrete as most of these fields form a highly optimized process for its own.

Sustainability versus Durability: It can be stated that durable materials fulfill the aspects of sustainability per definition, as durable materials are the basis for structures with long service life. However, the question arises whether these durable materials are always produced in a sustainable way.

\section{A Sustainable Built Environment Using Recycled Aggregate Concrete (RCA) :In the present study the influence of recycled coarse aggregate (RCA) obtained from three different sources having different ages of structures are on the properties of recycled aggregate concrete (RAC) are investigated and concrete mixes prepared with $100 \%$ and partial replacement of Natural coarse aggregate(NCA), Recycled Concrete Aggregate (RCA), Locally available Fine aggregates (Natural Sand ) and Admixtures and Mineral Admixtures were used in all mixes of Self Compacted Concrete (SCC).}

Development of SCC : in the beginning in 1983, the problem of the durability of concrete structures was a major Issue of Japan's Construction industry .The invention of concrete for durable concrete structures requires skilled manpower and Technology. The designs of Recent concrete and Reinforced concrete structures has become more advanced, the designed shapes and Contemporary features of structures are become increased . Furthermore, the gradual reduction in using of skilled workers and improvement of Durability of structures or Quality of construction in Japan's construction industry. One significant solution and achievement of Durable concrete structure independent of the quality of construction work is the using of self-compacting concrete(SCC), which can be compacted into every corner of a form work, purely by means of its own weight and without the need for vibrating compaction
Production of Self Compacting Concrete (SCC) Using Recycled Concrete Aggregate (RCA):- Preservation of the environmental, ecology and conservation Natural resources is the essence of Sustainable development. Recycling of concrete from the old concrete structures and Building Demolished Waste (BDW) to produce, recycle the aggregate suitable for structural and non-structural applications is fast emerging technologies and feasible construction operation.

The Employment of Self-Compacting Concrete (SCC) with Recycled Concrete Aggregates (RCA) is considered as a regular concrete which can be placed in to all Concrete applications of Construction and compacted under its selfweight without vibration effort, and which is at the same time, cohesive enough to be handled without segregation or bleeding. It is used to facilitate and ensure proper filling and good structural performance of restricted areas and heavily reinforced structural members furthermore the contrast reduction in the deployment of skilled workers to the Construction activities.

\section{CONCLUSION}

The construction industry has become one of the main contributors to the environmental pollution as the emission of carbon monoxide and other pollutants are the bi-products of many construction materials and also every individual focused towards effective utilisation of natural resources and to recycle and reuse the existing materials in and around available, it should not only sustainability is not about new materials but to reduce the effective wastages of present construction materials by applying an Environmental Management System thereby achieving Sustainability majorly.

The innovation of Self Compacting Concrete (SCC) with Recycled Concrete aggregate (RCA) , Natural Coarse Aggregate (NCA) with locally available fine aggregates ( sand ), marks an important milestone in improving the product quality and thus the efficiency of the concrete industry. Self-compacting concrete(SCC) has been used as a "special concrete" only in large general constructions. In order for self-compacting concrete(SCC) to be used as standard and regular concrete rather than special one, new systems and methods to be adopted for its design, manufacturing , and construction need to be established as per requirement of construction. The production of concrete as per basic requirements of high flow ability and segregation resistance as specified by EFNARC guidelines and as per Codal provisions are satisfied in fresh state of SCC. There is significant potential for growth of Recycled and Secondary aggregates as an appropriate and "green" solution to the anticipated increased world - wide construction activity.

Self-compacting concrete, which is suitable for placement in structures with congested reinforcement without vibration, requires special procedures for proportioning the mixtures and for verifying the suitability with trials. More trials are to be conducted further to check the self compatibility of 
concrete by reducing the cement content and by adding the other mineral admixtures such as Silica fume(SF), Ground Granulated Blast Furnace Slag (GGBS), Fly ash in light gray colour obtained from thermal power plant(FA), Rice Husk Ash(RHA), Stone Powders, etc. Water/cement ratios can be further reduced by using Viscosity Modifying Agents(VMA) in order to obtain good compressive strength values Standard Mix design procedures like modified NAN SU Mix design and etc., and test methods should be developed to improve the standards for better flow ability and strength as per Indian Standard conditions.

\section{REFERENCES}

[1] Department of Trade and Industry (2006) REVIEW OF SUSTAINABLE CONSTRUCTION 2006 [online]. UK: Department for Business Innovation and Skills. Available at: <http://www.bis.gov.uk/files/file34979.pdf>

[2] Construction and Demolition waste, Solid waste management manual, Ministry of Urban Development, Govt. of India, 2010, Chapter-4, Pages 57-63

[3] RILEM Recommendation: Specifications for concrete with recycled aggregates. Mater. Struct.1994, 27, 557-559.

[4] Hyungu Jeong (2011). "Processing and properties of recycled aggregate concrete", MS thesis, University college of Illinois, Urbana.

[5] RILEM TC 121(1994), "Specifications for concrete with recycled aggregates", Materials and Structures, Pages 557-559.

[6] Nan Su, K.C.Hsu (2001). "A simple mix design method for self compacting concrete", Cement and concrete research, Pages 1799-1807.

[7] Brouwers H.J.H. and H.J. Radix (2005). "SelfCompacting Concrete: Theoretical and experimental study" Cement and concrete Research, volume 35, Pages 2116-2136.

[8] EFNARC (2002), "Specifications and guidelines for Self compacting Concrete",

[9] Nanda R.L., S. Ratanaramig, P and Boonsiri S. Developing 'High performance concrete for hydraulic structure at Koldam.' the Indian Concrete Journal, Vol. 84, No.1, January 2010, pp. 21-33.

[10] Srinivas Vasam K. Jagannadha Rao \& K. Vasu (2012)- "Study on Self Compacting Concrete (SCC) and Recycled Coarse Aggregates (RCA) in the Present Construction Industry" at the "National Conference on Advances in Civil Engineering (ACE2012)" - May,2012

[11] Srinivas Vasam \& K. Jagannadha Rao(2013) - Use of SCC and RCA for Sustainable Construction -An Overview-IJRET- eISSN: 2319-1163 | pISSN: 23217308-Volume: 02 Issue: 11 | Nov-2013- pp. 629-633. 